\title{
CASE REPORT: THE HALL TECHNIQUE AS A METHOD OF CHOICE IN CASE OF ASYMPTOMATIC CLOSED PULPITIS IN PRIMARY TEETH
}

\author{
Milena Georgieva-Dimitrova \\ Department of Pediatric Dentistry, Faculty of Dental Medicine, Medical University of Varna
}

\begin{abstract}
INTRODUCTION: The ue of preformed metal crowns in minimally invasive methods of treatment, like the Hall technique, provides the option for these constructions to be used in daily outpatient practice in children with a small number/single carious lesions and negative attitude, who otherwise must be treated with pharmacological control of the behavior.
\end{abstract}

AIM: The aim of this article is to investigate the opportunity for treatment of the approximal dentin caries/ asymptomatic closed pulpitis with primary metal crowns (PMCs) using the Hall technique.

MATERIALS AND METHODS: The child's level of cooperation was assessed before the treatment using the Frankel scale. In this study a preformed metal crowns was used - Stainless Steel Primary Molar Crowns $\left(3 \mathrm{M} \mathrm{ESPE}^{\mathrm{rm}}\right)$, placed using the Hall technique. The paraclinical method of diagnostics and follow-up was segment $x$-rays of the crowned teeth - bitewing technique.

RESULT: A 5 -year old clinical case with an approximal carious lesion on tooth 84 is presented. Objective clinical criteria refer to asymptomatic closed pulpitis. Diagnostic radiograph has been made before the crown application. After two-year follow-up the x-rays show deposition of tertiary reactive dentin in the change of pulp chamber volume. The reaction of the pulp is clearly visible.

CONCLUSION: The Hall technique is a great alternative option for caries management and even for treatment of asymptomatic closed pulpitis especially for negative patients. In addition the longevity of PMCs overwhelms significantly the other filling materials and prevents secondary caries.

Keywords: Hall technique, PMC, carious lesion, treatment

\section{Address for correspondence: \\ Milena Georgieva-Dimitrova \\ Faculty of Dental Medicine \\ Medical University of Varna \\ 84 Tzar Osvoboditel Blvd \\ 9000 Varna \\ e-mail:dr.milena.georgieva89@gmail.com}

Received: April 16, 2019

Accepted: June 27, 2019

\section{INTRODUCTION}

Nowadays it is proven that the dental practitioners may provide long-term restoration sealing the caries with minimal or even without any excavation of the carious mass $(1,2)$. While making a clinical decision it is important to assess the amount of preserved hard tooth tissues, the level of root resorption - at least $3 / 4$ of the root length, existence of alveolar bone above the germ of the permanent tooth 
and clinical condition of the other teeth in the other quadrants $(3,4,5)$. In children with high caries risk the carious process runs fast and very aggressively. In most of the cases it is followed by a pulpal inflammation, which requires endodontic treatment and restoration with preformed metal crowns or even extraction and placement of space maintainers $(6,7,8)$. The indications for conventional fillings in primary dentition are relatively limited due to the two extreme methods of treatment: non-operational (preventive) treatment and the severe forms of caries with significant destruction of the hard tooth tissues (9). Some of the filling materials are not that effective regarding the carious process and eventually lead to the occurrence of secondary caries, as they leave the tooth surface unprotected and the borders of the fillings are uncovered and exposed to the conditions in the oral cavity (10). Preformed metal crowns cover all risk areas and that way decrease the risk of secondary caries (11). Another main reason for the failure of some of the filling materials is their fallout or the endodontic complications $(12,13)$. The main focus is on the approximal carious lesions, where the restorations experience these complications more often. In occlusal carious lesions almost every filling material is successful (14).

The use of preformed metal crowns in minimally invasive methods of treatment like the Hall technique, provides the option for these constructions to be used in daily outpatient practice in children with a small number/single carious lesions and negative attitude, who otherwise must be treated with pharmacological control of the behavior $(15,16)$. Out of all restoration materials they are the most durable in time in regard to the mechanical resistance and must be an option of choice for the restorations of deciduous dentition, especially in children with high caries risk (17).

\section{AIM}

The aim of this article is to investigate the opportunity for treatment of the approximal dentin caries/asymptomatic closed pulpitis with primary metal crowns (PMCs) using the Hall technique.

\section{MATERIALS AND METHODS}

The child's level of cooperation was assessed before the treatment using the Frankel scale. In this study a preformed metal crown was used - Stainless Steel Primary Molar Crowns ( $3 \mathrm{M}$ ESPE $\left.{ }^{\mathrm{rx}}\right)$, placed using the Hall technique. This technique includes: choice of the proper size of the crown, filling it with glass ionomer cement (GIC), positioning and cementing, removal of the excess cement, final placement, revision and cleaning. The paraclinical method of diagnostics and follow-up was segment x-rays of the crowned teeth - bitewing technique. Those $\mathrm{x}$ rays must be taken before the crown placement and for follow-ups on the first and second year - after the crown application. We followed-up for: normal physiological root resorption of the crowned primary tooth, pathological periapical and furcation changes in the underlying bone, internal and external pathological root resorption, pathological resoption of the interdental and interradicular bone. Control visitation were set on the $6^{\text {th }}, 12^{\text {th }}$ month and every year until the exfoliation of the tooth.

\section{RESULT}

A 5-year-old girl came to the dental clinic for a prophylactic visitation. The visual age confirmed the real one. Cooperative assessment was done before the treatment using the Frankel scale:

$\diamond$ Rating 1: Definitely Negative - refusal of treatment, forceful crying, fearfulness or any other overt evidence of extreme negativism

$\diamond$ Rating 2: Negative - reluctance to accept treatment, uncooperativeness, some evidence of negative attitude but not pronounced.

$\diamond$ Rating 3: Positive - acceptance of treatment; cautious behavior at times; willingness to comply with the dentist, at times with reservation, but patient follows the dentist's directions cooperatively.

$\diamond$ Rating 4: Definitely Positive - good rapport with the dentist, interest in the dental procedures, laughter and enjoyment.

We received information about the child's behavior from the parent by filling out an anonymous questionnaire.

The child fulfilled the criteria for negative behavior - unwillingness towards the dental treatment, non-cooperative, but not that clearly expressed, spontaneous rejection of the treatment. 
The caries risk assessment was based on the clinical examination, registration of the dental status (dmft index), active carious lesions and anamnesis using the American Academy of Pediatric dentistry (AAPD) tool, according to which the following risk factors have been assessed: frequency of carbohydrate intake, level of the oral hygiene, caries activity in parents, social status, protective factor - fluoride prophylaxis.

After the intraoral examination one irreversible active carious lesion was diagnosed on tooth 84 . The lesion was active, approximal, reaching the inner half of the dentin. The objective symptoms was a relatively large class II carious lesion on tooth 84 . The lesion was filled with food debris and soft, mild and moist dentin. During examination a provoked pain was established which faded away in less than 20 seconds after the irritation. There were no symptoms of irreversible pulpal inflammation, fistula or pathological mobility. There was no pain on vertical percussion. No pain on palpation in the apical area was registered (Fig. 1).

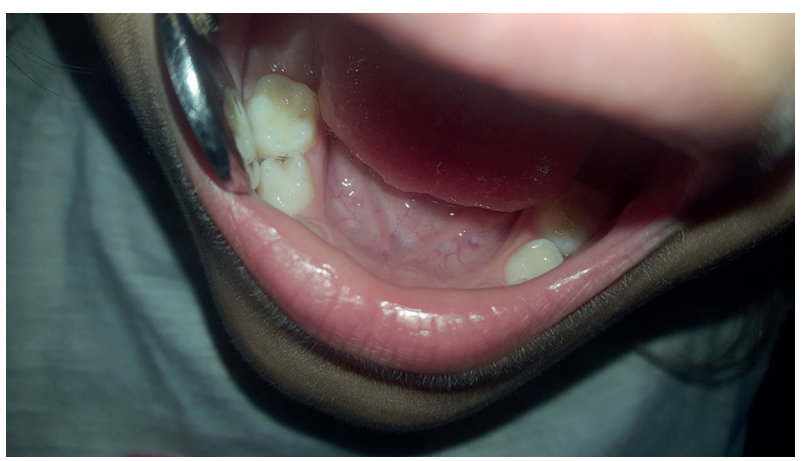

Fig. 1. Approximal carious lesion on tooth 84

Preliminary diagnostic radiography was done, helping for better assessment of the carious extension and its depth (Fig. 2). There was no radiography evidences for pathological periapical changes. No communication with the pulp chamber was visible on the $\mathrm{x}$-ray and there was a presence of a slight layer of dentin above the pulp. No resorption of the interradicular bone, neither internal and/or external pathological root resorption was observed.

The child definitely refused the use of rotary instruments and local anesthesia. The patient was negative so we decided to use the Hall technique as a method for caries management. In this clinical

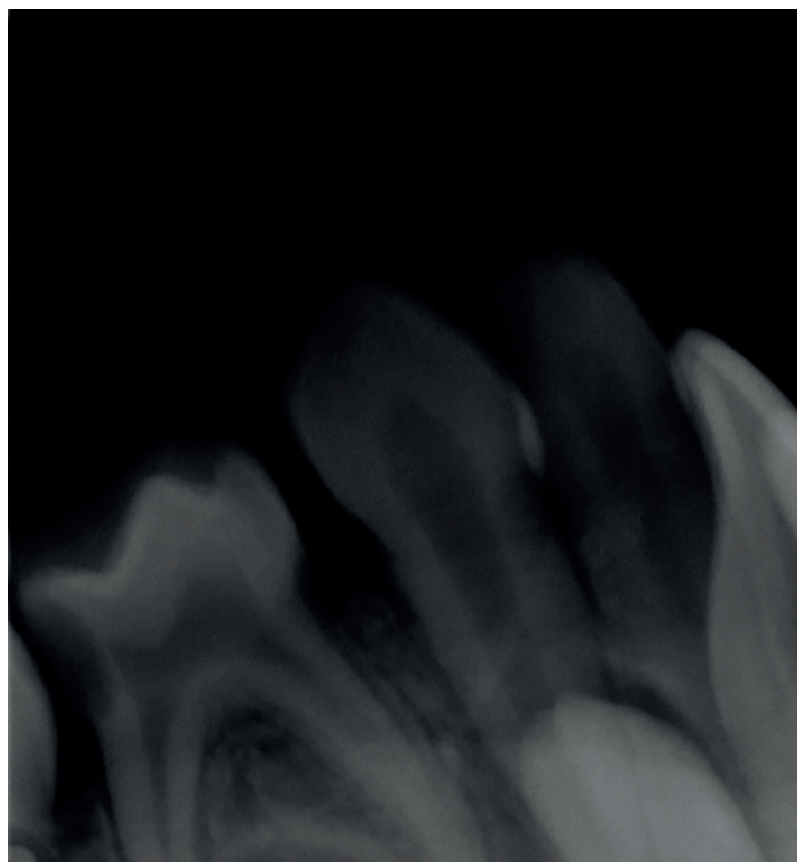

Fig. 2. Diagnostic radiograph before crown application

case PMC was used - Stainless Steel Primary Molar Crowns $\left(3 \mathrm{M} \mathrm{ESPE}^{\mathrm{Tx}}\right)$.

Tooth 84 was prepared for the crown application by cleaning the plaque and the food debris from the cavitated carious lesion.

\section{Technique of Crown Application:}

As step 1 a proper size of crown was chosen. At the beginning different sizes of PMCs were tried on to find one that covered the occlusal surface of the tooth but did not impinge on the teeth on either side, and there was no feeling of 'spring back'. In this case there was no need of orthodontic separators. The PMC was not pushed through the contact points (Fig. 3).

After the choice of a proper size of crown, its filling with GIC followed. GIC was mixed with nor-

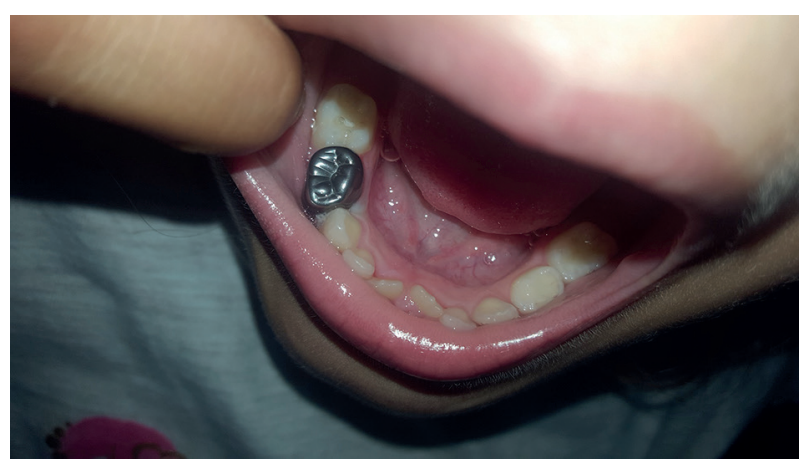

Fig. 3. Crown selection 
mal creamy consistency as when fixing individually designed crowns. The cement was placed in the preformed crown almost to the brim. The cement had to be positioned from the base to the brim of the crown to cover its walls. A resin modified GIC was used in this case.

Before placing the crown over the tooth it was well isolated with cotton rolls. The crown was placed evenly over the tooth and engaged in the approximal contact points using finger pressure to secure its position. While using a cotton roll or cotton wool, the child was asked to clench her teeth tightly fitting the crown to the tooth. Then it was carefully checked whether the crown was positioned evenly (Fig. 4). If necessary the clinician may fix the crown by strong pressure with their finger.

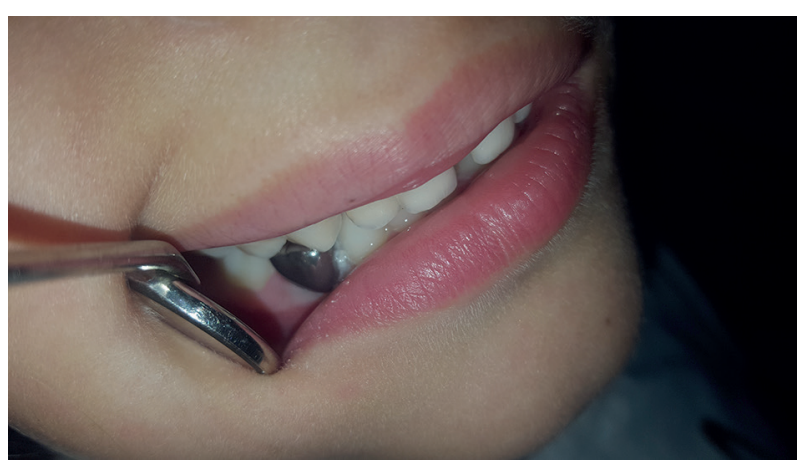

Fig. 4. Crown application

Immediately after fixing the crown child was asked to open her mouth to check positioning and remove excess cement while still wet. After careful evaluation of the position of the crown even while the cement was still soft, the child was instructed to bite down again with or without cotton (cotton wool) roll. It is likely that some more glass-ionomer would be extruded. The child should keep pressure on until the cement has set, to prevent the crown from rising back up and possibly compromising the seal. A final check of the crown was made and any excess cement was removed with hand excavator. Dental floss can be used to remove cement on approximal surfaces. The blanching of the gingiva usually disappears within minutes. The expectations were that the minimal occlusal discrepancy would be normalized after a few weeks (Fig. 5).

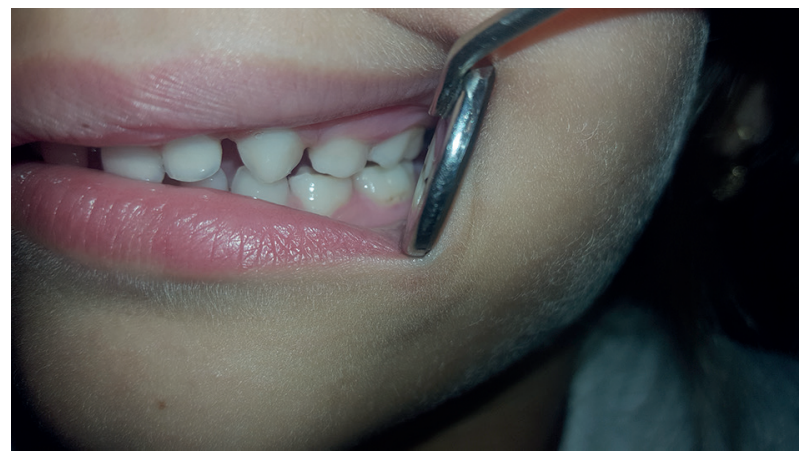

Fig. 5. Occlusion check right after crown application

Alongside with the treatment, during the control visitations, every child is being trained to improve its oral hygiene by motivation and remotivation and different forms of fluoride prophylaxis are also included (gels, varnishes and sealants). The followup visitations are set at every 6 months for a 2-year period with evaluation of the objective and subjective condition of the child, control radiographs, and photo documentation. The crown, roots of the tooth and the alveolar bone of the lower or upper jaw are visible

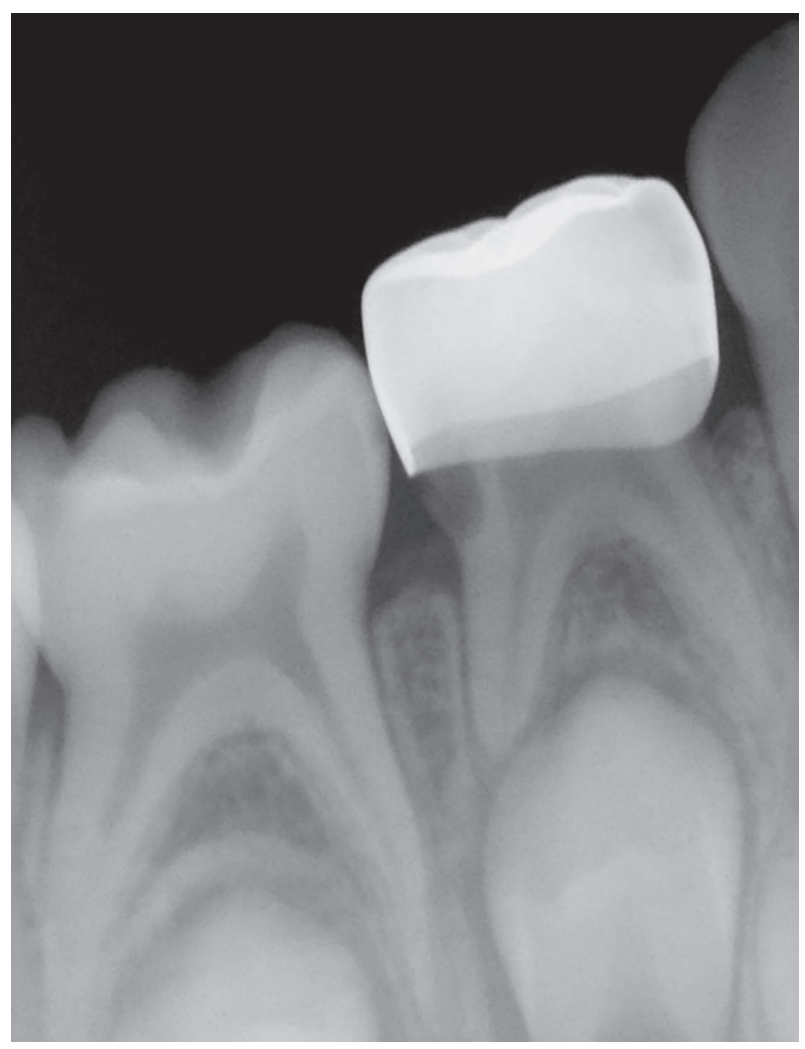

Fig. 6. Control radiograph 1 year after the treatment. The reaction of the pulp is clearly visible. Reactive dentin is formed in change of pulp chamber volume 
on the control radiographs. It is checked for: normal physiological root resorption, pathologic periapical and furcation changes, internal and external pathological root resorption, pathological resorption of the interdental and interradicular bone.

Despite that the crown on tooth 84 did not reach the apical area of the carious lesion, clinically and radiographically there were no visible complications of the carious process. The treatment was considered as successful (Fig. 6).

A two-year follow-up with $\mathrm{x}$-ray in this case showed formation of tertiary dentin. The pulp chamber was relatively reduced. No clinical symptoms such as fistulae, abscess and swelling or any subjective complaints were established (Fig. 7).

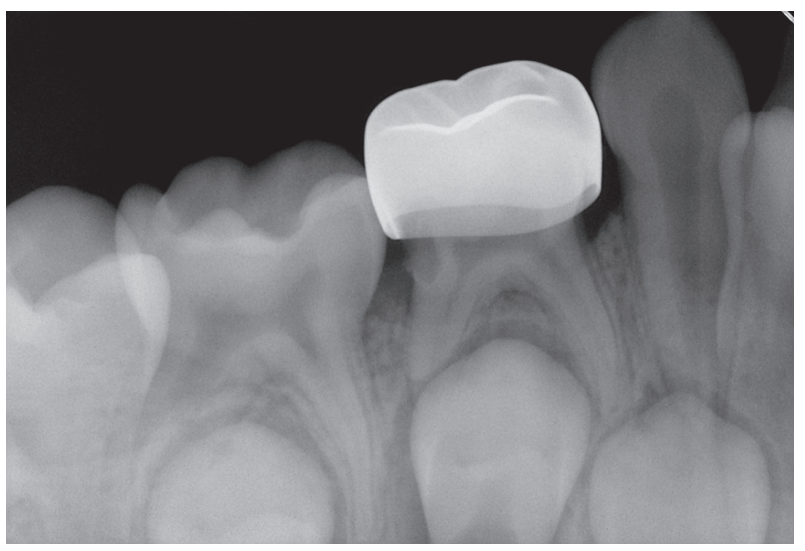

Fig. 7. Control radiograph two years after the treatment

Control radiograph was done two years after the crown application. The orifice of the distal root canal was obliterated. The tooth was vital. Normal root resorption continued. No clinical symptoms (pain, fistula, abscess) were observed. No pathological changes in the alveolar and interradicular bone were registered. There were no complaints from the patient concerning the occlusal vertical dimension (OVD) and temporo-mandibular joint.

The case was followed-up until the $4^{\text {th }}$ year after the crown application during the child's follow-up visitations. The child had no complaints, the tooth was liable to physiological exfoliation and was with $2^{\text {nd }}$ rate of mobility (Fig. 8).

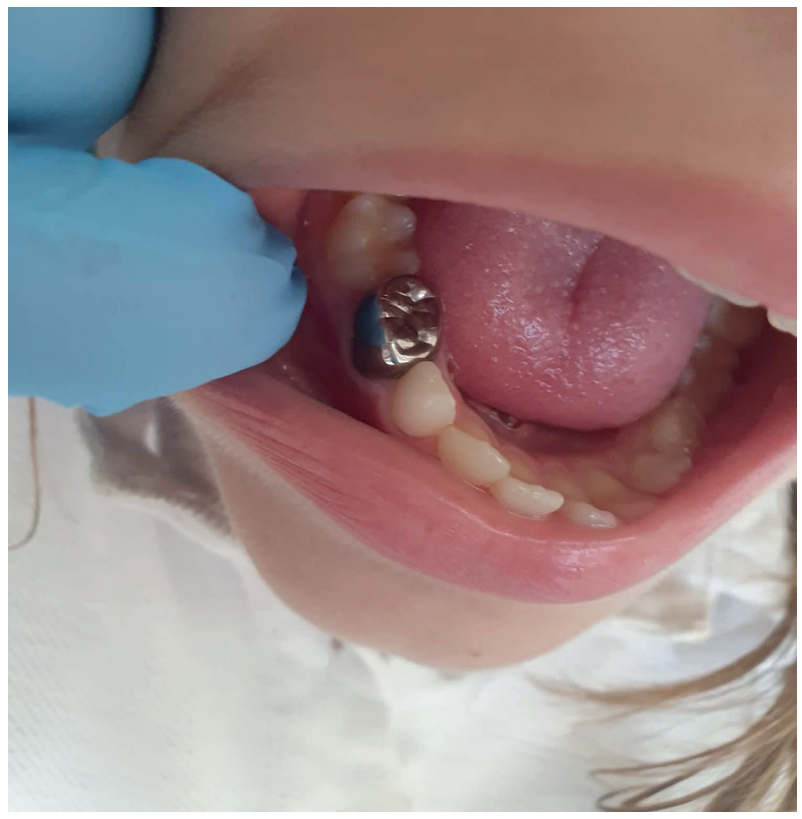

Fig. 8. Intraoral view after 4 years

\section{DISCUSSION}

The high prevalence of the caries in childhood age has been prove in many (18-25). Among 5- and 7 -year-old children the most affected group of teeth are the primary molars, and the most common type of caries is the approximal $(18,26,27)$. Complicated caries is one of the main reasons for premature loss of primary teeth in childhood age (7). The data received by Andreeva for children with premature loss of teeth show that at least half of the children have fear from dental treatment. She examines and assesses the behavior of the children using the Frankel scale and reports that the majority of children are slightly negative (8). The conventional excavation of deep carious lesions followed by fillings carries a high risk of endodontic complications, especially in cases with fractured marginal occlusal ridge $(10,12,13,28)$. The use of conventional materials requires strict protocol of application as well as the use of rotary instruments for caries excavation, which is hard to accept by the children $(29,30)$. The lack of cooperation from the children is often the reason for dental treatment under general anesthesia $(31,32)$.

New approach for treatment of primary molars with PMC is implemented by Evans et al. (33). The metal crowns are cemented without previous excavation of the caries or preparation of the tooth, and without necessity of local anesthesia. One of the 
main indications for the Hall technique is non-cooperative children, who hardly accept the conventional methods of treatment, which require local anesthesia (34). PMCs provide excellent sealing of approximal caries lesions of the primary molars and this way the carious process may be arrested $(15,17)$. In the literature there is data that the Hall technique is similar to indirect pulp capping, where a thin layer of carious dentin is left and sealed with definitive filling (34). The Hall technique is performed without application of local anesthesia (15) and after previous diagnostic x-ray and medical history excluding eventual pulp pathology $(6,35)$. Segment bitewing $\mathrm{x}$-rays are taken before crown placement and to follow-up the result of the treatment $(17,36,37,38)$.

At the moment long-term researches are going on in the UK, Australia and Asia and their results may change the recommendations for the use of this technique (6).

\section{CONCLUSION}

The Hall technique is a great alternative option for caries management and even for treatment of asymptomatic closed pulpitis especially for negative patients. In addition the longevity of PMCs overwhelms significantly the other filling materials and prevents from secondary caries.

\section{REFERENCES}

1. Simonsen R. From prevention to therapy: minimal intervention with sealants and resin composite materials. J Dent. 2011;39(Suppl 2):S27-33. doi: 10.1016/j.jdent.2011.11.001.

2. Wambier DS, dos Santos FA, Guedes-Pinto AC, Jaeger RG, Simionato MR. Ultrastructural and microbiological analysis of the dentin layers affected by caries lesions in primary molars treated by minimal intervention. Pediatr Dent. 2007;29(3):228-34.

3. Kidd EA, van Amerongen JP, van Amerongen WE. The role of operative treatment in caries control. In: Fejerskov O, Kidd EA (eds). Dental Caries: The Disease and its Clinical Management,. $2^{\text {nd }}$ edition. Oxford: Blackwell, Munksgaard,;2008.pp.356-65.

4. Scott JM, Mahoney EK. Restoring proximal lesions in the primary dentition: is glass ionomer cement the material of choice? N Z Dent J. 2003;99(3):65-71.

5. Yengopal V, Harnekar SY, Patel N, Siegfried N. Dental fillings for the treatment of caries in the primary dentition. Cochrane Database Syst Rev. 2009;(2):CD004483. doi: 10.1002/14651858. CD004483.pub2.

6. Cameron A, Widmer R. Handbook of Pediatric Dentistry. Germany: Mosby;2013.pp. 93-102.

7. Andreeva R, Georgieva M, Lichev D, Dimitrov E, Belcheva A. Local and general anesthesia and premature extraction of deciduous teeth. Medinform. 2016; 2:432-8.

8. Andreeva R, Georgieva M, Dimitrov E, Belcheva A. Connection between the childs behavior in the dental office and premature tooth extraction. Medinform. 2016; 1:409-413.

9. Hunter B. Survival of dental restorations in young patients. Community Dent Oral Epidemiol. 1985;18(5): 285-7.

10. Randall RC. Preformed metal crowns for primary and permanent molar teeth: review of the literature. Pediatr Dent. 2002;24(5):489-500.

11. Croll TP, Riesenberger RE. Primary molar stainless steel crown restoration. Quintessence Int. 1986;17(4):221-6.

12. Croll TP. Restorative dentistry materials for children: The 1990s and beyond. ASDC J Dent Child. 1993;60(4-5):260-2.

13. Kopel HM. Considerations for the direct pulp capping procedure in primary teeth: A review of the literature. ASDC J Dent Child. 1992;59(2):141-9.

14. Chadwick BL, Evans DJ. Restoration of class II cavities in primary molar teeth with conventional and resin modified glass ionomer cements: a systematic review of the literature. Eur Arch Paediatr Dent. 2007;8(1):14-21.

15. Splieth $\mid \mathrm{CH}$. Revolution in pediatric dentistry.Germany: Quintessence;2011.pp.21-35.

16. Andreeva R.General anesthesia and sedation in pediatric dentistry-definition, purpose, advantages and disadvantages. Varna Med Forum.2018;7(2):112-6.

17. Innes NP, Evans DJ, Stirrups DR. The Hall Technique; a randomized controlled clinical trial of a novel method of managing carious primary molars in general dental practice: Acceptability of the technique and outcomes at 23 months. BMC Oral Health 2007;7(1):18.doi: 10.1186/1472-6831-7-18.

18. Dimitrov E, Georgieva M, Andreeva R, Dimova-Gabrovska M, Arnautska H. Caries prevalence 
among 5-7 - year-old children in Northeast Bulgaria. J IMAB. 2017;23(3):1633-6.

19. Andreeva R. Premature loss of primary teeth in children with early mixed dentition. Prophylaxis with space maintainers. Dissertation.Varna; 2016. pp.60-8 (in Bulgarian).

20. Ambarkova V, Jankulovska $M$, Stevanovic $M$, Sotirovska-Ivkovska M, Zafirovska-Ivanovska B, Guguvcevski LJ. Dental caries experience among six-year-old children in Republic of Macedonia. J DentOrofac Surg. 2016; 1-5.

21. Bagramian RA, Garcia-Godoy F, Volpe AR. The global increase in dental caries. A pending public health crisis. Am J Dent. 2009;22(1):3-8.

22. de Amorim RG, Figueiredo MJ, Leal SC, Mulder J, Frencken JE. Caries experience in a child population in a deprived area of Brazil, using ICDAS II. Clin Oral Investig. 2012;16(2):513-20. doi: 10.1007/ s00784-011-0528-9.

23. Dental Public Health Intelligence Team. Oral health survey of five-year-old children 2015. A report on the prevalence and severity of dental decay. Public Health England. 2016: 8-24.

24. Peneva M, Rashkova M, Doichinova L. Age distribution of caries lesions in children's permanent teeth - a basis for the choice of a therapeutic solution. J IMAB.2007;13(2):58-60.

25. Skeie MS, Espelid I, Skaare AB, Gimmestad A. Caries patterns in an urban preschool population in Norway. Eur J Paediatr Dent. 2005;6(1):16-22.

26. Corrêa-Faria P, Paixão-Gonçalves S, Paiva SM, Pordeus IA. Incidence of dental caries in primary dentition and risk factors: a longitudinal study. Braz Oral Res. 2016;30(1). doi: 10.1590/1807-3107BOR2016.vol30.0059.

27. Peretz B, Ram D, Azo E, Efrat Y. Preschool caries as an indicator of future caries: a longitudinal study. Pediatr Dent. 2003;25(2):114-8.

28. Andreeva R.Assessment of different types of materials of children treated under general anesthesia. MedInform;2018; 2:432-8.
29. Scottish Dental Practice Board. Annual Report 2001/2002. Edinburgh: NHS Scotland, 2002.

30. Tickle M, Milsom K, Kennedy A. Is it better to leave or restore carious deciduous molar teeth? A preliminary study. Prim Dent Care. 1999;6(4):127-31.

31. Andreeva R. Indications for dental treatment under general anesthesia. Scr Sci Med. 2018;50(3): 26-9.

32. Andreeva R. Assesment of the indications for dental treatment of children under general anesthesia. Scr Sci Med Dent. 2018;2(1):49-52.

33. Evans DJP, Southwick CAP, Foley JI, Innes NP, Pavitt SH, Hall N. The Hall technique: a pilot trial of a novel use of preformed metal crowns for managing carious primary teeth. Scottish Dental Practice Based Research Network. Available at: http:// www.dundee.ac.uk/tuith/Articles/rt03.htm. Accessed: February 1, 2011.

34. Innes NP, Evans DJ, Bonifacio CC, Geneser M, Hesse D, Heimer M, et al. The Hall Technique 10 years on: Questions and answers. Br Dent J. 2017;222(6):478-83.

35. Duggal MS, Day P. Operative treatment of dental caries in the primary dentition. In: Welbury RR, Duggal MS, Hose MT, editors. Paediatric Dentistry. $3^{\text {rd }}$ edition. Oxford: Oxford University Press; 2005. pp.149-66.

36. Innes NP, Ricketts DN, Evans DJ. Preformed metal crowns for decayed primary molar teeth. Cochrane Database Syst Rev. 2007;(1):CD005512. doi: 10.1002/14651858.CD005512.pub2.

37. Innes $N$, Stewart M, Souster G, Evans D. The Hall Technique; retrospective case-note follow-up of 5-year RCT. Br Dent J. 2015;219(8):395-400. doi: 10.1038/sj.bdj.2015.816.

38. Pitts NB, Nugent ZJ, Smith PA. Scottish Health Boards' Dental Epidemiological Programme (SHBDEP) Report of the 1999 - 2000 Survey of 5-yearold children. University of Dundee; 2000. http:// www.dundee.ac.uk/dhsru/publications/shbdep99/ 